Revista Española de Antropología Americana ISSN: 0556-6533

https://doi.org/10.5209/REAA.63696

\title{
Un recorrido teórico sobre el consumo desde una mirada antropológica: hacia las prácticas alimenticias y su estudio a partir de la zooarqueología ${ }^{1}$
}

\author{
Jimena Doval ${ }^{2}$
}

Recibido: 22 de agosto de 2017 / Aceptado: 18 de marzo de 2019

Resumen. El artículo presenta una síntesis sobre las aproximaciones teóricas en torno al consumo en diversas disciplinas de las Ciencias Sociales, con el fin de comprender su tratamiento en relación con las prácticas de alimentación. El énfasis en este último punto se dirige a la indagación sobre la alimentación particularmente en el campo de la Arqueología. Se presenta un caso de estudio zooarqueológico (fortín La Perra, La Pampa, Argentina, fines del siglo XIX) para ilustrar y discutir las perspectivas sostenidas por la autora.

Palabras clave: prácticas de consumo; alimentación; zooarqueología; antropología.

\section{[en] A Theoretical Overview about Consumption from an Anthropological Gaze: Towards Food Practices and Their Study from Zooarchaeology}

\begin{abstract}
This paper presents a synthesis of the theoretical approaches around consumption in different Social Sciences, in order to understand their treatment as to feeding practices. The emphasis in this last point is directed towards food inquiries in Archaeology. A zooarchaeological case study (Fort La Perra, La Pampa, Argentina, late $19^{\text {th }}$ century) is presented to illustrate and discuss the perspectives upheld by the author.
\end{abstract}

Keywords: consumption practices; feeding; zooarchaeology; anthropology.

Sumario. 1. Introducción. 2. Antropología del consumo: una mirada sobre la praxis social. 3. La alimentación como consumo. 4. Una aproximación zooarqueológica: el caso del fortín La Perra (la Pampa seca a fines del siglo XIX). 5. Otros restos materiales ligados al consumo. 6. Una mirada desde las fuentes narrativas y documentales. 7. Discusión y conclusiones. 8. Referencias.

Cómo citar: Doval, Jimena. 2018. «Un recorrido teórico sobre el consumo desde una mirada antropológica: hacia las prácticas alimenticias y su estudio a partir de la zooarqueología». Revista Española de Antropología Americana 48: 163-184.

\footnotetext{
1 La investigación en que se basa este trabajo fue financiada a través de una beca doctoral del Consejo Nacional de Investigaciones Científicas y Técnicas (CONICET) y de los sucesivos proyectos UBACyT dirigidos por la Dra. Ana Aguerre y la Dra. Alicia Tapia.

2 Instituto de Arqueología, Facultad de Filosofía y Letras, Universidad de Buenos Aires, Argentina. dovaljimena@gmail.com
} 


\section{Introducción}

Los estudios sobre consumo han abarcado una diversidad de disciplinas científicas, aunque su referencia remite, por lo menos en el sentido común, al campo de la Economía. El tema se ha abordado de forma muy amplia en las Ciencias Sociales, con un creciente esfuerzo hacia la interdisciplinariedad. Esta última dificulta dar cuenta de un corpus teórico único propio de la Sociología, la Economía, la Historia o la Antropología, producto de la construcción holística del andamiaje conceptual de cada una de dichas disciplinas en torno al consumo. Ello ha llevado a la interacción e integración de conceptos alimentados en diferentes campos del conocimiento. Algunos de los temas principalmente desarrollados se han dirigido, entre otras temáticas, al estudio del consumo cultural (García Canclini 1984); a la cultura material (Appadurai 1986; Miller 1987); a los cambios introducidos en la sociedad capitalista (Glennie 1995; Vries 2008); a la identidad y las relaciones de poder (Bourdieu 1990; Miller 1995); y a las economías de mercado modernas y el marketing (Arnould y Thompson 2005; Shove et al. 2009).

El objetivo del presente trabajo es realizar una síntesis del devenir de las aproximaciones sobre las prácticas de consumo en Antropología y Arqueología, prestando especial atención a la influencia que han tenido desde otras disciplinas. A la luz de ese derrotero, analizamos su impacto sobre el estudio de la alimentación como una alternativa a los esquemas teóricos tradicionales, especialmente aquellos sostenidos desde la Arqueología. Luego se presenta resumidamente la investigación zooarqueológica de un asentamiento militar de la Pampa seca de fines de siglo XIX, completado con la referencia a otros tipos de restos obtenidos en él y a fuentes narrativas y documentales, como ilustración y aplicación de un estudio del consumo desde la perspectiva aquí planteada.

\section{Antropología del consumo: una mirada sobre la praxis social}

«People produce things to consume, consume things to produce, consume things in the process of social reproduction, and produce social beings and social relationships» (Wurst y McGuire 1999: 196).

La producción teórica antropológica en torno al consumo se ha constituido en una influencia importante para otras disciplinas a la hora de la construcción de su andamiaje conceptual. Ello es notorio a través de la repetición de citas de trabajos antropológicos, desde los clásicos hasta los enfoques más recientes (Callejo 1995; Tamayo Téllez 2011). Por su parte, en la Antropología se advierte el uso de un importante corpus proveniente principalmente de la Sociología y de la Economía y, a la vez, el campo definido como Antropología económica ha mostrado una fuerte influencia en el devenir teórico desarrollado en el seno de la Economía. Poner en consideración cuáles han sido sus preceptos principales nos permitirá comprender algunas de las tendencias teóricas en torno al consumo que han influido en las Ciencias Sociales. 


\subsection{La Antropología económica y su visión sobre el consumo}

Las principales discusiones sobre el consumo se podrían delinear a partir de dos grandes posturas y el extenso debate que se generó entre ambas: el formalismo y el sustantivismo (Herskovits 1952; Burling 1976; Trinchero 1998). El formalismo fundó sus planteamientos principales en la teoría económica clásica, considerando que el consumo se basa en la maximización de la utilidad que realiza la unidad doméstica a partir de la elección racional que sus miembros efectúan sobre medios escasos y fines específicos (Trinchero 1998; Molina 2004). Si bien dicha elección se hizo depender de tres factores -la renta, los precios y los gustos-, sólo se logró explicar la variación del consumo en torno a la variación de los precios, la renta y su utilidad en el mercado. En este sentido, las decisiones individuales basadas en los gustos o aquellas ajenas a lo monetario quedaron fuera de la explicación clásica. Una de las grandes críticas que se dirigió al uso de la teoría económica clásica en Antropología fue que esos planteamientos habían sido pensados para sociedades con economía de mercado auto-regulado, en detrimento de aquellas tradicionalmente abordadas desde la mencionada disciplina (Burling 1976; Molina 2004). A partir de dicha concepción, se reprodujo acríticamente la metáfora del Homo economicus, presuponiendo «un mundo sumamente idealizado, en el que los individuos actúan con una total información y previsión, adoptando tan sólo decisiones económicas racionales para la maximización de sus fines, sin aparecer en este esquema teórico ningún tipo de limitación cultural» (Kaplan 1976: 217-218). Se observó que la Antropología -a la luz del formalismo- había reproducido los preceptos de la economía clásica a partir de una concepción funcionalista del consumo como un modo de satisfacer las necesidades fisiológicas (Michael y Becker 1973). Asimismo, como sugiere Miller (1995), esos planteamientos han negado la presencia de un consumidor $-\mathrm{y}$ de su autonomía como uno de los aspectos que permite explicar el consumo-.

Las críticas a la postura clásica fueron realizadas por los exponentes del sustantivismo como una reacción a las concepciones económicas ortodoxas sobre la escasez, además de a la aplicación de concepciones pensadas para sociedades capitalistas de mercado a los casos abordados por la Antropología (Polanyi 2007 [1944]; Trinchero 1998; Molina 2004). Los sustantivistas propusieron que la actividad económica se configura como un mecanismo de integración social que interactúa en todas las esferas de una sociedad, siendo imposible explicar la acción económica en términos utilitarios. En este sentido, no pueden diferenciarse las esferas política, cultural y religiosa de la económica, debido a que se configuran como áreas fuertemente imbricadas.

Estas dos grandes posturas -formalismo y sustantivismo- permiten sintetizar las principales discusiones dentro de la teoría económica sobre el consumo durante los siglos XIX y XX. Asimismo, se configuraron como la influencia de las diversas concepciones del consumo que encontramos en las Ciencias Sociales. Si bien el desarrollo de la postura formalista fue anterior al sustantivismo, ambas han convivido en el tiempo y pueden observarse resquicios de una y otra en los diferentes postulados.

Estas dos perspectivas oscilan entre una serie de binomios opuestos que subyacen a las concepciones que cada una propone y contemplan al consumo y al sujeto que lo realiza de diferentes modos: pasivo-activo, opresión-libertad, destrucción-reproducción, alienación-apropiación. Por supuesto, entre los dos extremos existen otras posturas que han sentado su posición con respecto al consumo, como es el caso de las marxistas, aunque no será menester de este trabajo desarrollarlas. 


\subsection{Una construcción dialógica entre la Sociología y la Antropología}

Desde la Sociología, se ha producido un gran corpus teórico que ha sido retomado en el marco de los estudios antropológicos sobre el consumo. Estos han enfatizado una perspectiva social y cultural, considerando que las cosas poseen un valor simbólico (Baudrillard 1983; García Canclini 1984; Certeau 1990; Bocock 1996; Rotman 1996; Miele 2006). Si bien dentro de dichos postulados existió una amplitud teórica, en todos los planteamientos se encontró presente la idea del consumo como un hecho social, relacional y activo (Callejo 1995). Esta concepción permitió superar la idea de que las cosas poseen un valor y un uso inherente, como también la de que el consumo responde meramente a la satisfacción de las necesidades, obviando que da cuenta de las relaciones sociales y de poder. En este sentido García Canclini (1984) planteó que «El consumo no tiene por finalidad únicamente la posesión de un objeto o la satisfacción de una necesidad material, sino también definir y reconfirmar significados y valores comunes, crear y mantener una identidad colectiva» (1984: 77). Esto sugiere que el espacio de reflexión por excelencia sobre el consumo es el de las prácticas cotidianas, donde no sólo se reproducen éstas, sino que se producen y negocian significados en el hacer (Tamayo Téllez 2011). En estas concepciones, la vida cotidiana, el consumo y las cuestiones identitarias adquieren vital importancia para la teoría social. En este camino, Bourdieu (1990), propone que el consumo se configura como un modo de diferenciación social que se forja a través del habitus (Bourdieu 1977). De acuerdo con ello, se conforma como un sistema de comunicación simbólico donde se reflejan y reproducen las diferencias sociales y la construcción identitaria (Douglas e Isherwood 1979; Douglas 1984; Miller 1987, 1995). Así, el proceso de apropiación -material y simbólica- de los objetos por parte de los sujetos y los significados que entran en juego son el eje neurálgico de la discusión propuesta por Bourdieu (1977) y retomada por Miller: «... el objeto es transformado por su íntima asociación con un individuo o grupo social particular, o con la relación entre éstos» (1987: 190).

Estas perspectivas de estudio se han reproducido en la Sociología, la Historia y la Antropología, enfatizando el análisis de estos procesos en el contexto de la vida cotidiana (Goffman 1997; Giddens 1984; Braudel 1986; Miller 1995; Shove et al. 2009). Siguiendo en esta línea, el filósofo Michel de Certeau (1990) ha estudiado el consumo diferenciando entre tácticas y estrategias como medios para dar cuenta de las relaciones sociales y de poder, definiendo la estrategia como la manipulación que realiza un sujeto con poder, mientras que la táctica sería un recurso del débil para contrarrestar la estrategia, aprovechando sus intersticios. Así, la táctica es utilizada a partir de la imposición de una fuerza externa, audaz frente al poder y por lo tanto a la estrategia (Certeau 1990). En este sentido, las tácticas no sólo reflejarían rechazos hacia lo impuesto por el poder, sino que podrían dar cuenta de la resignificación de los objetos dentro del sistema en el cual se encuentra inmersos. Estas posturas permiten superar la construcción materialista del consumo que asume la pasividad de los consumidores (Appadurai 1986; Miller 1987; Callejo 1995).

Tomando algunos elementos de los postulados de Bourdieu, el historiador Jan de Vries (2008) ha afirmado que en las Ciencias Sociales se ha abordado el consumo desde una dualidad entre la acción y la estructura, produciéndose un movimiento pendular entre posturas opuestas: por un lado, el consumo como decisión de un sujeto activo y autónomo y, por otro, un enfoque donde el sujeto es pasivo y receptivo 
ante lo que la estructura le impone. Sin embargo, Vries plantea la necesidad de abordar el consumo desde una posición intermedia, considerando que se constituye como un fenómeno cultural independiente de las fuerzas económicas. En este sentido, el individuo posee la capacidad de interactuar con el mercado y superar su rol de ser un simple receptor, generando en su acción cotidiana un «capital de consumo» forjado a partir de la experiencia y un constante acto de descubrimiento que puede o no modificar sus gustos y elecciones.

Más allá de las diversas aproximaciones que hemos mencionado de modo sintético, solo hace poco tiempo que el consumo -como punto final del tradicional circuito económico- ha tomado importancia en la producción académica, dado el tradicional énfasis en la producción (Miller 1995).

En la sociedad actual la idea de consumo de masas lleva implícito un carácter negativo, pero el consumo ha llevado consigo desde antes una imagen negativa, de destrucción, por oposición a la creación que implica la producción. Esta concepción se remonta a Durkheim o Rousseau, que sostuvieron que el consumo lleva a la pérdida de integridad del ser humano (Miller 1995). Fue reforzada, además, por la clásica separación del ciclo económico en cuatro fases internas - producción, distribución, circulación y consumo-, en la que el consumo se opone a la producción y se liga a lo destructivo; se configuró como la alienación de la vida en la sociedad moderna (Vries 2008). Por su parte, Miller (1995) propone abordar el consumo desde la cultura material trascendiendo esa negatividad, entendiendo que no se constituye como un punto final, sino como una forma de negociación con la producción, donde los bienes retornan para la creación de las relaciones sociales. Esto ha sido delineado por Appadurai (1986) en su postulado sobre la vida social de los objetos: un objeto no es una escisión del pasado que lo refleje de manera objetiva, sino que posee estructuras de significación mucho más complejas, en las que se debe tomar en cuenta la relación entre el objeto y su biografía social. Esa relación está en constante movimiento, cambio y negociación según el contexto particular y los actores sociales implicados, que a través de su interacción lo invisten de un significado particular (Gosden y Marshall 1999). En este sentido, las cosas o los alimentos no tienen un significado único, entrando en juego variables como el contexto en cual se insertan, los individuos que los poseen/consumen y/o los otros objetos con los que se relacionan, pudiendo cambiar sus significados y absorber nuevos.

\section{La alimentación como consumo}

«...en cada bocado vivimos a diario nuestra doble condición de seres culturales y biológicos» (Delgado Salazar 2000: 1).

La alimentación se constituye como un tópico presente en la Historia y la Antropología desde su constitución como disciplinas (Miller 1995; Garine 1999; Mintz y Du Bois 2002; Pérez Samper 2010). Así, los registros tempranos de viajeros, misioneros, historiadores y antropólogos se dirigieron a describir los modos en que los pueblos se alimentaban. Sin embargo, no es hasta mediados del siglo XX que los trabajos comenzaron a sistematizarse en un corpus de estudio específico. A partir de la década de 1960, bajo la corriente historiográfica francesa de los Annales, los estudios sobre la alimentación han tenido un gran desarrollo, ejerciendo una fuerte 
influencia en el campo de la Antropología (Díaz Méndez 2005; Pérez Samper 2010). Esta perspectiva se ha centrado en el análisis de las transformaciones alimentarias que han sufrido las sociedades modernas, estableciendo una fuerte escisión entre los estudios que analizan los modos de producción y aquellos que hacen hincapié en el consumo (siendo estos últimos más abundantes). Las investigaciones sobre prácticas alimentarias en las sociedades contemporáneas han entrado en el debate sobre la desestructuración e individualización de la alimentación a través de la indagación en las diferencias de clase, la organización y calidad de la alimentación, la accesibilidad, los procesos de producción y consumos, entre algunos de los campos en desarrollo (Mintz y Du Bois 2002; Díaz Méndez 2005). Así, dentro de la Historia, la escuela francesa ha tenido una fuerte impronta en el análisis de los aspectos identitarios de la alimentación y el consumo, reivindicando los estudios de la historia culinaria (Flandrin y Montanari 2004 [1996]; Pérez Samper 2010). Muchos de los trabajos actuales en Sociología van dirigidos al estudio de la alimentación en el marco de la sociedad de consumo y el aumento del individualismo y la soberanía alimentaria (Díaz Méndez 2005; Di Masso Tarditti 2012).

En el marco de la Antropología de la alimentación se ha reconocido la convivencia entre la necesidad biológica y los aspectos simbólicos y culturales en el acto de comer (Contreras 1992). El interés creciente por el estudio de la alimentación se relaciona con su potencial para dar cuenta -más allá de lo nutricional- de la dinámica social que subyace en el acto de comer, como las relaciones sociales y la propia concepción cultural del comer (Carrasco Henríquez 2007). Así, Aranda Jiménez (2008: 11) ha afirmado:

«Los grupos sociales no sólo comen nutrientes que cubren sus necesidades subsistenciales, sino comida, es decir, sustancias seleccionadas, preparadas y organizadas según normas culturales. La alimentación es un fenómeno social y cultural en donde intervienen factores muy diversos en la definición de qué es apto y qué no para ser consumido, y en qué condiciones debe realizarse».

El antropólogo Jack Goody (1995) ha estudiado la alimentación a partir del planteamiento de diversas fases entendidas como herramientas de análisis: obtención, distribución, preparación, consumo y desecho. Dichas fases reprodujeron parte del circuito económico tradicional definido a partir de sus cuatro fases internas: producción, distribución, circulación y consumo. Si bien esta distinción posee un valor heurístico, hay que tener la precaución de no reproducir la idea de la separación entre producción y consumo como un hecho real y objetivo (Wurst y McGuire 1999), un error común que se ve plasmado en la producción académica antropológica que tradicionalmente abordó la alimentación sólo considerando las primeras fases, indagando sobre qué se cazaba o recolectaba, como sinónimo de la producción. En las últimas décadas se ha optado por una concepción más integral del consumo, que permite romper con la imagen del consumidor pasivo y contribuye a entender la interrelación de cada una de las etapas del proceso. Así, las diversas etapas del circuito (producción, distribución, consumo y desecho) se comprenden a la luz de una compleja red de procesos y significaciones que brindan capacidad de agencia a los sujetos y objetos imbricados (Carroll 1999). De esta manera, el consumo no se configura como el momento final del proceso, sino que influye en las elecciones desde el momento de la obtención/producción del alimento y se cristaliza en el momento de su ingesta o «consumo»: 
«...different approach to consumption sees production and consumption as dialectically linked rather than distinctly separate activities. From this perspective, any act of production entails consumption and any act of consumption results in production, a linkage captured in notions of productive consumption and consumptive production»» (Paynter 2000: 176).

Dentro de dicha perspectiva se encuentran los estudios que abordan los foodways, concibiendo al alimento como una parte indivisible de la vida cotidiana que genera diferencias entre los grupos sociales (Bourdieu 1977, 1988). En este sentido, se configuran como objetos de identificación y clasificación social (Douglas e Isherwood 1979).

\subsection{La aproximación desde la Arqueología}

El interés en la alimentación ha sido un tema recurrente en el desarrollo de la Arqueología desde el estudio de los primeros homínidos hasta nuestros días. Así, los estudios sobre la subsistencia y las prácticas alimenticias han tenido un fuerte desarrollo frente a la discusión de la caza, el carroñeo y la recolección en relación con la organización social, la división sexual del trabajo, el cuidado del prójimo, las prácticas de obtención y consumo de alimentos, entre otros aspectos (Leakey 1971; Binford 1981; Issac 1983; Shipman 1984; Potts 1984; Blumenschine 1992; Rose y Marshall 1996, entre otros). La alimentación fue entendida clásicamente como parte de la «subsistencia», con una fuerte mirada economicista y una concepción biologista, donde la maximización de la utilidad y la acción racional van de la mano con la satisfacción de las necesidades fisiológicas. En los clásicos de la Antropología y la Arqueología, esa concepción está presente, por ejemplo, en la afamada conferencia Man the Hunter (Lee y DeVore 1968) o en la extensa discusión sobre la caza y el carácter carroñero de los primeros homínidos (Binford 1981; Isaac 1983; Shipman 1984, entre otros); ambas muestran que el principal interés se puso en los modos de obtención de la comida, en el rendimiento calórico del alimento conseguido y en la maximización de su utilidad dentro de la dieta. Así, la acción de los sujetos se explicó en el marco de la búsqueda constante del equilibrio entre costo y beneficio. Otra acepción comúnmente utilizada se refirió a la equiparación de la subsistencia con los modos de producción de una sociedad, como la recolección y la caza, la explotación agrícola o sociedad industrial (Berdichewsky 2002). Bajo estas premisas, a partir de la década de 1960, la Antropología y la Arqueología buscaron construir modelos que abordaran la subsistencia teniendo en cuenta factores ambientales, estacionales, sociales y materiales (Schiffer 1972; Binford 1981; Spencer-Wood 1987) y detectaran la existencia de patrones de comportamiento regulares con los que explicar el registro arqueológico. Esas posturas se comprenden a la luz de la consolidación de la Arqueología y la búsqueda del cientifismo que caracterizó al procesualismo de la década de 1960 (Nastri 2004); en esa búsqueda se enfatizó la mirada sobre el objeto y el metodologismo extremo llevó a concepciones del consumo que avalan la idea del Homo economicus. Si bien la aplicación de estos modelos ha producido avances disciplinares fundamentales, creemos que su escaso poder heurístico ante la agencia humana, y también ante la predicción y explicación de los comportamientos sociales, los han convertido en una aproximación que es necesario superar.

La indagación sobre la alimentación en la Arqueología está constreñida al carácter promediado y fragmentado del registro arqueológico (Samuel 1996). En este sen- 
tido, su planteamiento dentro de la Arqueología se ha centrado tradicionalmente en el registro zooarqueológico, por su ubicuidad y conservación, aunque también se han incluido las evidencias arqueobotánicas, los restos bioarqueológicos, el estudio de residuos orgánicos sobre restos cerámicos y filos líticos, de fitolitos e isótopos, entre algunas de las perspectivas que permiten indagar en las múltiples dimensiones de la alimentación (Zurro 2006; Babot, Marschoff y Pazzarelli 2012; entre otros). Cada una de esas líneas de investigación se complementa perfectamente con las demás, permitiendo la conjunción de diversas perspectivas y registros con diferentes grados de integridad y de escala, enriqueciendo la visión sobre las prácticas alimenticias. Sin embargo, la zooarqueología ha sido una de las fuentes principales de acceso a la información sobre el consumo de alimentos. Dicha especialización tuvo su nacimiento y consolidación bajo una fuerte influencia positivista que ha condicionado su desarrollo hasta la actualidad. El impulso que tomó bajo el procesualismo en los años sesenta y setenta ha generado un énfasis en la tarea del zooarqueólogo basada en la primacía del objeto (Shanks y Tilley 1987; Nastri 2004). Así, el comportamiento humano frente a las elecciones de qué comer es evaluado con escalas de optimización y con un fuerte condicionamiento ambiental.

A partir de la década de 1980, la Arqueología post-procesual -a través de sus diversas y eclécticas corrientes- introdujo un cambio sobre la mirada del rol del comportamiento de los sujetos y buscó sus causas simbólicas, culturales o identitarias más allá de lo económico (Hodder 1988). La alimentación comenzó a estudiarse como una práctica social donde interactúan aspectos culturales en todas sus fases (Hodder 1988; Beaudry et al. 1996; Mintz y Du Bois 2002). Estas posturas contribuyeron a considerar el consumo de alimentos no como una mera práctica de subsistencia destinada a cumplir con la necesidad biológica de nutrirse, sino como un acto de consumo donde interactúan factores identitarios y sociales (Douglas e Isherwood 1979). A partir de dicha perspectiva, desde la Arqueología se ha comenzado a indagar en las cuestiones alimentarias más allá de los clásicos estudios zooarqueológicos o arqueobotánicos. En este sentido, se integraron en el estudio otros objetos vinculados con la alimentación, como utensilios, vajilla, ollas y fuentes escritas, constituyendo un corpus de datos adicionales que permiten dar cuenta de las prácticas de consumo como un acto complejo e integrado en el que entran en juego una diversidad de factores (Beaudry et al. 1996; Marschoff 2007, 2008; Babot, Marschoff y Pazzarelli 2012, entre otros):

«Desde una perspectiva arqueológica, el estudio de las trayectorias de los alimentos y las prácticas culinarias debe considerar a los comportamientos y sentidos asociados a la comida, pero fundamentalmente puede apelar desde una posición privilegiada a las materialidades que les son propias: los alimentos, los elementos artefactuales y ecofactuales, los rasgos y estructuras, sus asociaciones y contextos...» (Babot, Hocsman et al. 2012: 239).

En las últimas décadas, el surgimiento de nuevos avances científico- tecnológicos ha permitido ampliar el espectro de posibilidades de los estudios de la alimentación; es el caso de los análisis químicos sobre diversos artefactos y los estudios de isótopos estables sobre restos bioarqueológicos (Schoeninger y Schurr 1994; Babot, Marschoff y Pazzarelli 2012). Así, el panorama sobre la alimentación se ha ido haciendo más complejo, incluyendo diversas líneas de evidencia que permiten discutir el proceso con la profundidad que se merece. 


\section{Una aproximación zooarqueológica: el caso del fortín La Perra (la Pampa seca a fines del siglo XIX)}

Los estudios arqueológicos sobre los asentamientos de frontera se remontan a la década de 1990 y se centraron en la investigación de sitios al sur y oeste de Buenos Aires -ubicados cronológicamente entre 1778 y 1885 - tales como fuertes y fortines militares, tolderías indígenas, pulperías, estancias y campos de batalla (Gómez Romero y Ramos 1994; Austral y Rochietti 1999; Gómez Romero y Spota 2006; entre otros). Estos asentamientos permiten dar cuenta de la dinámica sociocultural que se suscitó en el territorio al sur de la actual provincia de Buenos Aires, que las autoridades coloniales, primero, y el flamante Estado, luego, pretendieron dominar para su incorporación como tierras productivas. Dentro de esta problemática, hemos estudiado diversos asentamientos de frontera instalados durante fines del siglo XIX en la actual provincia de La Pampa (Tapia 2008; Landa 2010; Pineau 2011; Montanari 2013; Doval 2017; entre otros). En esta ocasión se presenta el caso del Fortín La Perra con la finalidad de dar cuenta de cómo fue aplicada la perspectiva de estudio aquí planteada en torno a las prácticas de consumo en general y a la alimentación en particular desde un análisis zooarqueológico.

El fortín La Perra (FLP en adelante) se encuentra ubicado en la localidad de Bajo El Carbón ( $36^{\circ} 53^{\prime} 6,90^{\prime \prime}$ de latitud sur y $65^{\circ} 15^{\prime} 7,7^{\prime \prime}$ de longitud oeste) en el departamento Loventué (La Pampa, Argentina). Formó parte de una línea de fortines militares -con cabecera en Victorica y Gral. Acha- que funcionaron entre 1883 y 1885 como retaguardia del avance de las tropas militares hacia la Patagonia (Figura 1). Su función era realizar tareas de vigilancia sobre el territorio recientemente conquistado por el flamante Estado Nacional. Su ubicación topográfica da cuenta de dicha función, dado que FLP fue instalado en la cúspide de un cerro de tosca de $350 \mathrm{msnm}$, desde

Figura 1. Ubicación geográfica del fortín La Perra (La Pampa, Argentina).

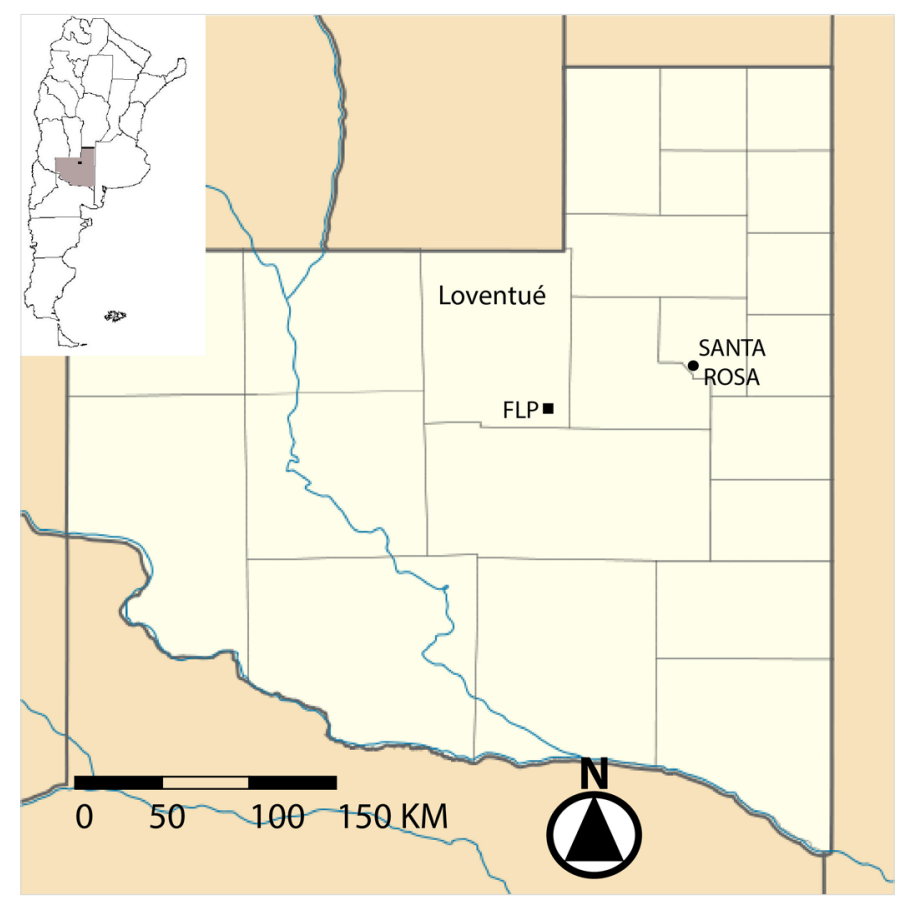


donde se poseía una amplia visibilidad del entorno, un estratégico dominio del paisaje circundante y el control de las vías de circulación o rastrilladas (Tapia 2008).

Entre los años 1998 y 2000 la excavación de seis cuadrículas y cinco sondeos, que cubrieron una superficie de $30 \mathrm{~m}^{2}$, permitió recuperar 5.560 restos arqueológicos que de acuerdo a sus características permitieron corroborar su vinculación con una ocupación militar de fines del siglo XIX. El mayor porcentaje de materiales recuperados se trató de restos óseos $(71 \%)$, seguidos por los fragmentos vítreos $(27 \%)$ y los metales (1\%); el 1\% restante comprende restos de cuero, lítico, loza y otros. El análisis de los diversos artefactos permitió realizar inferencias sobre la circulación y obtención de esos bienes en el espacio fronterizo y la discusión de los aspectos vinculados a la provisión del ejército, las prácticas cotidianas (cocina, limpieza, confección de artefactos, etc.), así como también las relaciones de poder y estatus que se suscitaron en un asentamiento militar (Pineau y Landa 2009; Landa 2010; Pineau 2011; Doval y Tapia 2013; entre otros). A continuación se sintetizan los resultados del estudio zooarqueológico, para luego vincularlos con otros materiales relacionados con prácticas de consumo, así como también con la información que brindan las diversas fuentes narrativas y documentales.

\subsection{Resultados del estudio faunístico}

Los restos faunísticos de FLP fueron recuperados en la mayoría de las unidades de excavación, aunque su distribución estuvo marcadamente concentrada en la cuadrícula VI donde se hallaron el $82,9 \%$ de los restos faunísticos del sitio. De acuerdo con la distribución espacial y la reconstrucción de la historia tafonómica del conjunto, se interpretó que la alta densidad de restos faunísticos de la cuadrícula VI correspondería a un sector de descarte secundario (Doval y Tapia 2012).

El conjunto faunístico se compone de 4.120 especímenes óseos, 1.363 placas dérmicas de armadillos y 314 fragmentos de cáscaras de huevo de Rhea americana (ñandú). E1 60\% del conjunto pudo ser identificado con algún grado de especificidad, mientras que el $40 \%$ restante no pudo ser identificado dado su alta fragmentación y ausencia de zonas diagnósticas. La composición taxonómica mostró una amplia diversidad de especies, 17, de las cuales 13 corresponden a mamíferos y 4 a aves (Cuadro 1). En la mayoría de los taxones se hallaron indicios de procesamiento antrópico, excepto en Sus scrofa, Canis familiaris, Nothura sp. y Buteo sp., los cuales se hayan representados por un único espécimen óseo. En el caso de Ardea sp., las huellas registradas se vincularon a su uso como instrumento, lo que no descarta su consumo alimenticio y el posterior aprovechamiento como materia prima de los elementos óseos (Doval y Tapia 2013; Doval 2017).

El análisis de diversos indicadores, como las huellas de procesamiento (cortes, negativos de impacto), fracturas antrópicas y la termoalteración, nos permitió realizar inferencias sobre las prácticas culinarias y de consumo implicadas para cada una de las especies representadas en el conjunto. Las huellas sobre los diversos elementos y taxones nos permitieron observar que los restos óseos desechados muestran las diversas etapas del procesamiento. Así, la presencia de autópodos articulados de varios taxones dio cuenta de la matanza de la presa y su procesamiento primario dentro del sitio. Las huellas encontradas sobre superficies articulares en elementos del esqueleto apendicular (tibia, fémur y húmero) y del esqueleto axial (vértebras, costillas y escápula) permitieron observar la desarticulación y troceado de las di- 
Cuadro 1. Abundancia taxonómica del conjunto del Fortín La Perra

\begin{tabular}{lrc}
\hline \multicolumn{1}{c}{ Taxón } & NISP $^{*}$ & MNI $^{* *}$ \\
\hline Bos taurus & 89 & 2 \\
Lama guanicoe & 3 & 1 \\
Equus caballus & 7 & 1 \\
Felis concolor & 8 & 1 \\
Ovis aries & 69 & 3 \\
Dolichotis patagonum & 22 & 1 \\
Ozotoceros bezoarticus & 17 & 2 \\
Leopardus sp. & 1 & 1 \\
Licalopex gymnocercus & 27 & 1 \\
Canis familiaris & 1 & 1 \\
Sus scrofa & 1 & 1 \\
Chaetophractus villosus & 525 & 23 \\
Chaetophractus vellerosus & 62 & 3 \\
Rhea americana & 281 & 8 \\
Nothura sp. & 1 & 1 \\
Ardea sp. & 1 & 1 \\
Buteo sp. & 1 & 1 \\
\hline
\end{tabular}

* Número de especímenes individuales.

** Número mínimo de individuos.

versas unidades de consumo, como parte del procesamiento secundario y terciario. En este sentido, en el mismo espacio de basural se encontraron representadas las diversas etapas del procesamiento y consumo de las presas. Las técnicas culinarias elegidas y el tamaño de las presas implicaron diferentes grados de troceado, siendo el hervido el que mayor intensidad de fragmentación ha requerido (Kent 1993). Ello pudo ser inferido en algunos casos a partir de las evidencias de huellas, fracturas y la acción ígnea.

En síntesis, se observó lo siguiente entre las especies domesticadas. En el caso de la vaca (Bos taurus), las huellas de corte y los patrones de troceado observados sobre las vértebras cervicales, escápulas y diáfisis de huesos largos indicarían su consumo a través de comidas de olla. Las huellas y termoalteración sobre las hemimandíbulas sugieren el consumo de la lengua. La gran cantidad de costillas con evidencias de termoalteración y huellas daría cuenta de su cocción mediante el asado. En el caso del caballo (Equus caballus), se evidenció el troceado de la escápula y la diáfisis de una tibia, lo que podría asociarse a su preparación para la cocción en olla. En el de la oveja (Ovis aries), dada la alta frecuencia de huellas de procesamiento sobre las hemimandíbulas, se sugiere el consumo de la lengua. Las huellas antrópicas relacionadas con la desarticulación y descarne, como también los indicadores de termoalteración, permiten inferir que la oveja pudo prepararse tanto asada de modo completo como también segmentada en las unidades menores, cuartos y costillares. Las huellas registradas sobre el cuerpo de las vértebras lumbares podrían vincularse con la extracción del lomo utilizado para preparaciones asadas, hervidas $\mathrm{y} / \mathrm{o}$ fritas.

Con respecto a las especies silvestres, el venado de las pampas (Ozotoceros bezoarticus) mostró un patrón de termoalteración y huellas de procesamiento, asociados al asado de los cuartos traseros. Los elementos de guanaco (Lama guanicoe) son escasos y dan cuenta de la desarticulación del tarso y la fragmentación del fémur para el consumo de médula. En la mara (Dolichotis patagonum) no se observaron 
signos de termoalteración por cocción y se registró sólo una huella sobre una tibia. En cuanto a las especies del puma (Felis concolor) y el zorro gris (Licalopex gymnoncercus), se registraron huellas sobre metápodos y autópodos, lo que podría considerarse un indicio de la extracción del cuero. Sin embargo, esto no quita que pudieran haber sido procesados para el consumo de su carne, tal como evidencian las huellas de corte y la termoalteración sobre los elementos óseos del puma (Doval 2017; Doval y Tapia 2012, 2013).

La gran cantidad de restos óseos de armadillos evidencia su elevado consumo, sobre todo en el caso de los peludos (Chaetophractus villosus). La alta frecuencia de huellas registrada en todos los elementos de los dasipódidos indica tareas vinculadas al descarne y desarticulación sobre huesos largos y costillas. Las placas dérmicas presentaron poca alteración térmica, lo que nos permitiría establecer que las presas fueron mayormente asadas mediante su exposición indirecta (Doval 2017). Asimismo, un espécimen muestra indicios de haber sido hervido (Doval y Tapia 2013; Doval 2017). Entre las aves, el ñandú (Rhea americana) presenta una alta frecuencia de elementos óseos ricos en carne y grasa, como la cintura pélvica (picana), el radio y húmero (alones) y la tibia, con huellas de descarne. Las huellas sobre las tibias darían cuenta de su fractura intencional para la extracción de grasa. La gran cantidad de fragmentos de huevos de ñandú dan cuenta de por lo menos el consumo de dos unidades, según se calculó a través del peso siguiendo la metodología de Quintana (2008). La termoalteración sobre 16 de ellos sugiere su exposición sobre las brasas para cocinarlos.

\section{Otros restos materiales ligados al consumo}

La integración del estudio faunístico con los resultados arrojados en el análisis de otros materiales hallados en el sitio ha enriquecido las interpretaciones a las que hemos arribado. Algunos objetos de metal hallados en el FLP resultaron de interés para discutir los aspectos vinculados al consumo, como es el caso de una lata de sardinas en conserva y varios fragmentos de olla de hierro de fundición (Landa 2010). La presencia de la olla de fundición de hierro y su tamaño estimado $(35 \mathrm{~cm}$ de diámetro, que correspondería a un recipiente de 15 litros de capacidad aproximadamente), apoya la evidencia arqueofaunística sobre la preparación de comidas en olla, inferida a partir del troceado de las piezas óseas en pequeñas porciones. Por su parte, la lata de sardinas podría dar cuenta de prácticas de consumo diferenciadas entre la oficialidad y la tropa, por tratarse de un bien de lujo para ese contexto (Landa 2010).

El análisis de los restos vítreos contribuyó a pensar sobre el rol del consumo de bebidas alcohólicas en estos asentamientos, como también a discutir los modos de circulación dentro del espacio fronterizo (Pineau y Landa 2009). El consumo de una amplia variedad de bebidas alcohólicas de diversos tenores etílicos (ginebra, vino, cerveza, aguardiente whisky, entre otras) se realizó a través de redes extraoficiales, posiblemente a partir de su comercialización por parte de mercachifles o pulperías (Pineau 2011). En este sentido, la evidencia provista por el registro arqueológico mostró un consumo repetido de bebidas alcohólicas, que implican la existencia de prácticas consensuadas frente a esta contravención. En este sentido, Pineau y Landa (2009) analizaron este escenario en relación con los conceptos de táctica y estrategia de Certeau (1990), y se preguntaron: 
«¿Qué explicación le podemos dar a esta contradicción? ¿Es esta tolerancia una táctica de los oficiales con el objetivo de volver armónica la convivencia con la tropa en estos lugares de aislamiento y marginalidad, para evitar las deserciones, en donde incluso la vida propia de los oficiales se vería amenazada? ¿O por el contrario, el consumo de alcohol en los fortines constituye una táctica de la tropa, un claro desafío a las autoridades, una continuación de costumbres inveteradas?» (Pineau y Landa 2009: 148).

En ambos casos se constituiría como una táctica que permitió sobrellevar las dificultades que acarreaba la vida en la frontera. Este mismo ejemplo podría aplicarse a otros ámbitos del consumo como la alimentación y los recursos cárnicos, tal como veremos a continuación.

\section{Una mirada desde las fuentes narrativas y documentales}

El estudio de los relatos de viajeros y militares ha permitido acceder a las experiencias de diversos agentes que vivieron, transitaron y/o prestaron servicio en el espacio de frontera. Si bien presentan un sesgo vinculado a la construcción discursiva de cada sujeto -que en algunos casos poseen un componente fuertemente etnocéntrico-, permitieron vislumbrar la existencia de prácticas sociales compartidas por los diversos actores sociales a lo largo del tiempo en el mismo espacio (Doval 2017).

La comparación entre el listado taxonómico de las especies halladas en FLP y aquellas mencionadas para el consumo alimenticio en las fuentes escritas sobre sitios militares (y otros asentamientos de frontera) ha permitido identificar semejanzas y diferencias entre ambos tipos de registro (Cuadro 2). Los vacunos se configuran como la especie más mencionada, luego le siguen en importancia el caballo, el ñandú y el venado de las pampas o gama. La oveja se relaciona mayormente con contextos indígenas y criollos, mencionándose en un solo caso para un asentamiento militar. Sin embargo, en los perfiles taxonómicos de los fortines es la especie doméstica más abundante. Otras especies, como el armadillo, el guanaco, la mara, la vizcacha, el zorro y el gato montés, son registradas en las prácticas de alimentación del espacio fronterizo, pero sin aludir a un grupo social específico. Finalmente, la ausencia de menciones sobre el consumo de cerdo resulta un aspecto interesante, dado que se encontró representado en el registro arqueológico.

Los funcionarios y militares expusieron constantemente las situaciones de carencia vividas en los fortines, producto del desabastecimiento y/o la escasez de alimento. Esas penurias no sólo se redujeron a la alimentación, sino que también incluyeron el equipamiento, armamento y vestimenta, entre otros:

«El mate y el café hechos en el mismo fogón donde hay un asado de yegua, viene con el mismo olor y gusto. Después hay el sufrimiento moral de presenciar la carneada de esos animales, que nó está uno acostumbrado a ver matar y que por ser tan inmediatos compañeros y servidores del hombre, se contemplan casi como prójimos (...) Estos señores proveedores han logrado que aquí hasta la ciencia hieda a potro» (Olascoaga 1974 [1880]: 80).

Es importante remarcar que el consumo de las presas tanto domésticas como silvestres no se limitó a los recursos cárnicos y con finalidad alimenticia, sino que los restos óseos, la grasa y la piel o las plumas se configuraron como subproductos 
Cuadro 2. Taxones mencionados en las fuentes historicas y tipos de asentamiento en que fueron registrados

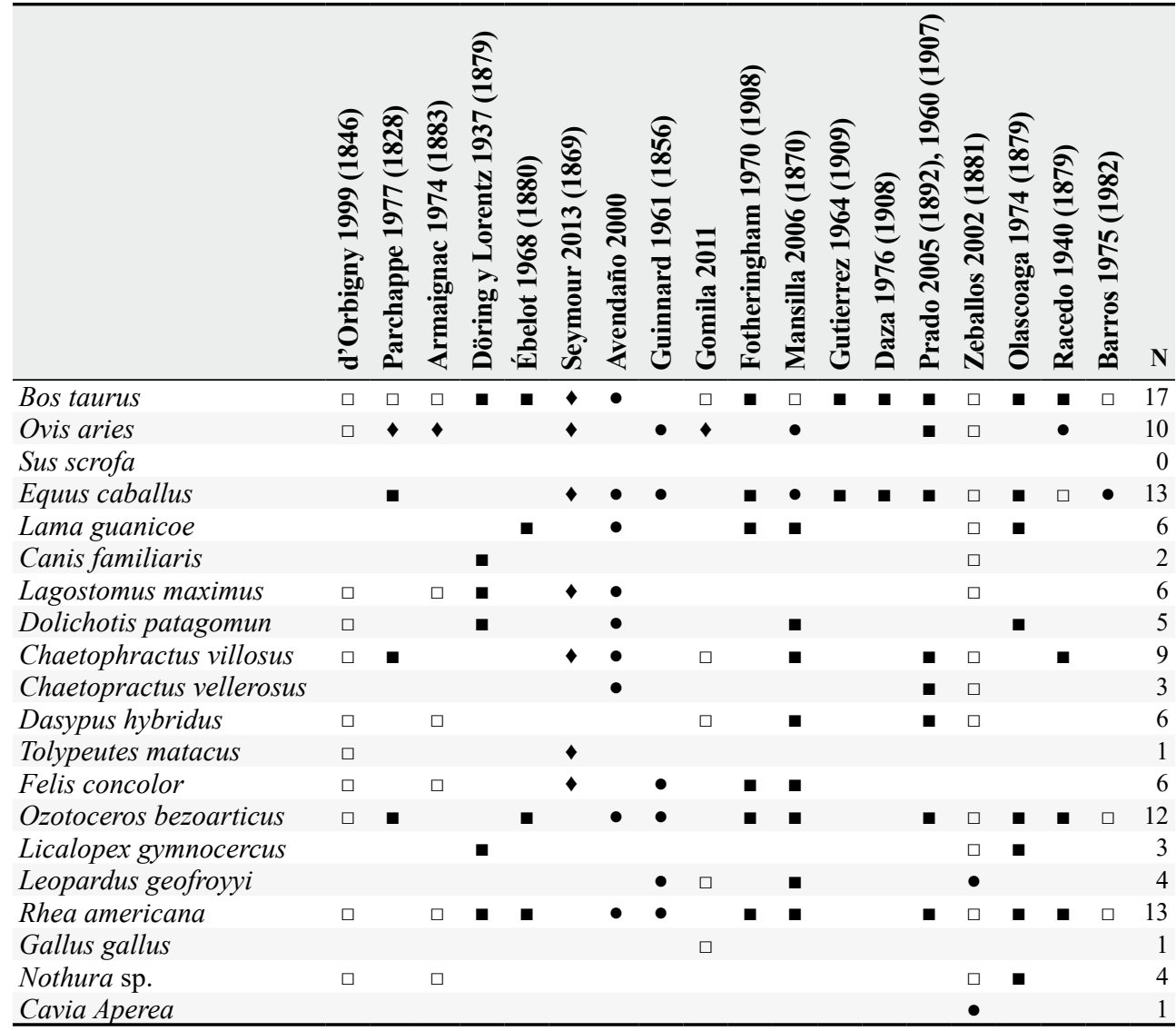

- En campamento militar. $\bullet$ En asentamiento indígena. $\diamond$ En asentamiento criollo. $\square$ En sitio militar/indígena/criollo.

que fueron aprovechados con diversos fines, como los medicinales (Guerrino 1979). Asimismo, los cueros, pieles y plumas también fueron utilizados como moneda de cambio para conseguir otros artículos en los circuitos comerciales ubicados en el interior del espacio fronterizo, usufructuado tanto por los indígenas como por aquellos que estuvieron asentados en sitios militares:

«¿Quieres pasar paisana? Le dijo la china civilizada en lengua Pampa, ¿Pasar, para qué?, respondió. Si trae cueros o algo que vender aquí se los pueden comprar estos hombres, le replicó la india cristiana, y de conversación resultaron conocidas y hasta parientes, y luego nomás se trabó amistad y negocio por los cueros de tigre» (Gomila 2011: 140).

La consulta de documentos oficiales se centró en aquellos generados por el Ministerio de Guerra y Marina, así como otra documentación proveniente de otras reparticiones castrenses. Con ese objeto se consultaron varios repositorios como el Servicio Histórico del Ejército, el Archivo General de la Nación y la Biblioteca del Ministerio de Defensa de la Nación. En torno a la provisión de alimentos cárnicos, los diversos documentos establecen que se debía proveer cada punto con tropillas 
en pie de ganado vacuno, el cual debía componerse de individuos menores a los tres años de edad. Sin embargo, el análisis del perfil etario de los vacunos reveló que no se cumplió a rajatabla con estas condiciones. Respecto al perfil etario, en FLP se registraron dos vacunos, uno de ellos menor y otro mayor a los tres años. Por otra parte, en el perfil taxonómico del FLP es evidente que los vacunos no fueron la especie mayoritariamente consumida. A pesar de ello, los documentos señalan que, durante los últimos años de ocupación del ejército en el espacio fronterizo (1883-1885), la provisión se llevó a cabo de la mejor manera posible. No obstante, en relación con otros artículos se mencionan los problemas que acarreó la lejanía de estas instalaciones, como sucedió en el caso del fortín Victorica ( $82 \mathrm{~km}$ al norte de FLP):

«Ha habido ocasiones que el vestuario no ha llegado con regularidad, pero esto no ha sido culpa de una repartición determinada, sino de las largas distancias y escasos medios de transporte con que cuenta el pueblo, y cada día se hacen más escasos por causa de su avance creciente» (Memoria... 1885: 106).

La mención del ganado ovino es escasa en los documentos oficiales y se relaciona con momentos puntuales en que las malas condiciones climáticas invernales requirieron el reemplazo de los vacunos (seis ovinos suplían a una vaca). El registro arqueológico mostró que fue un recurso más frecuente de lo que estipularon los registros oficiales. Es interesante remarcar que, en los registros sobre los arreos incautados a los indígenas, el ganado lanar se cuenta como el más abundante, en concordancia con la información arqueológica (Spota 2010). Esto plantea la posibilidad de que, más allá de su provisión «oficial»-probablemente como parte de un arreglo interno entre proveedores y jefes de frontera-, también pudieron ser capturados como ganado disperso.

\section{Discusión y conclusiones}

En términos generales, la discusión sobre el consumo ha girado en torno a la concepción del proceso económico y al rol de los sujetos en él, más allá de la corriente teórica de adscripción o del campo del conocimiento en el que se indague. Las concepciones clásicas conciben al sujeto de modo pasivo y actuando en busca de la maximización del beneficio y la minimización del costo. Desde esa postura, el consumo se constituye en el momento final del ciclo económico y se liga a la idea de destrucción. En el otro extremo se ubican nociones sobre el consumo que lo caracterizan como parte de un circuito económico complejo en constante interacción, donde los sujetos son activos y donde las decisiones se toman no sólo por factores económicos, sino por elecciones relacionadas con lo cultural y lo simbólico.

En nuestra concepción -sin caer en los extremos-nos encontramos más cercanos a la segunda posición. Como ejemplo de ello hemos expuesto un caso de estudio propio desde una perspectiva zooarqueológica. Como parte del proceso de investigación, se ha podido añadir al estudio faunístico un abundante corpus de fuentes narrativas y documentales (relatos de viajeros, cautivos y militares, partes oficiales consultados en el Servicio Histórico del Ejército, documentación del Ministerio de Marina y Guerra). A partir de la síntesis del estudio desarrollado, se pone de manifiesto la necesidad de adoptar una mirada sobre las prácticas de consumo alimenticio atenta a algo más complejo que la alimentación en el sentido fisiológico. 
Los resultados del estudio faunístico y su integración con diversas fuentes de información (arqueológicas e históricas) han permitido dar cuenta de la particularidad del consumo alimenticio en un asentamiento militar de fines de siglo XIX $\mathrm{y}$, asimismo, exponer algunas contradicciones entre lo dicho y reglamentado y lo que fehacientemente muestra la materialidad de los hechos. La evidencia faunística indica un consumo diversificado con un predominio de especies silvestres de pequeño y mediano porte. En este sentido, el consumo de alimentos -refiriéndonos aquí solamente a los recursos cárnicos- no se limitó solamente a los insumos que debían ser provistos oficialmente, sino que recurrió a actividades cinegéticas, las cuales estaban vedadas salvo previa autorización. Sin omitir que las situaciones de escasez pudieron condicionar esta elección, también es necesario considerar las elecciones culinarias sobre qué comer y la oportunidad de degustar algunas preciadas presas silvestres. Cabe remarcar que las mismas no sólo eran capturadas por el interés en su carne; otros recursos secundarios, como la piel o las plumas, se configuraron como moneda de intercambio que posibilitaba acceder a otros productos. Por otro lado, determinadas especies también pudieron ser buscadas por las propiedades medicinales otorgadas a la grasa y las vísceras, aunque este aspecto no puede ser comprobado arqueológicamente (Guerrino 1979). Creemos que todo este escenario responde a la situación del fortín La Perra que, por su ubicación geográfica y temporal, se configuraría como una ocupación «marginal» (Doval y Tapia 2013; Doval 2017, entre otros).

La presencia de otros elementos arqueológicos relacionados con las prácticas alimenticias (ollas de fundición de hierro y recipientes vítreos) ha permitido dar cuenta de la existencia de diversas escalas de inserción y circulación de objetos en el espacio fronterizo (macro-, meso- y microescala). Los modos de circulación de estos objetos siguieron múltiples vías, incluyendo el transporte personal, el aprovisionamiento oficial y el intercambio con comerciantes locales (Tapia 2008; Landa 2010; Pineau 2011, entre otros). Así, la presencia tanto de bebidas etílicas como de objetos metálicos responde a la circulación de productos importados en espacios alejados de las urbes, como correlato de la explosión del capitalismo industrial y financiero a escala global (Hobsbawn 1998a, 1998b). Los fragmentos de ollas globulares de hierro hallados en el sitio indican los modos de procesar y cocinar los alimentos. La aparición en el mismo de una lata de sardinas puede apuntar a comportamientos de comensalidad vinculados a diferencias de rango militar o estatus social.

A partir del análisis expuesto, se pone de manifiesto una aproximación a la alimentación en la que el comportamiento de los sujetos evita ser leído como una constante búsqueda de maximización de sus beneficios. Se propone romper con la concepción estática y economicista sobre la alimentación tradicionalmente sostenida a través de los estudios faunísticos. Se hace hincapié en la alimentación como un hecho social que condensa e interrelaciona una multiplicidad de aspectos de la cotidianidad, tales como -entre muchos otros- las necesidades fisiológicas, la etnicidad, las relaciones de poder y los factores económicos (Minz y Du Bois 2002; Babot, Marschoff y Pazzarelli 2012). Por ello, en la interpretación del registro faunístico del fortín La Perra se toma en consideración una diversidad de aspectos a la hora de comprender la elección de las especies y sus modos de prepararlas e ingerirlas. Desde esa perspectiva, se hace posible adoptar una mirada integral de la alimentación entendida como parte de las prácticas de consumo de los diferentes actores sociales del espacio fronterizo. 
Agradecimientos. La investigación fue financiada con una beca doctoral del Consejo Nacional de investigaciones Científicas y técnicas (CONICET) y de los sucesivos proyectos UBACyT dirigidos por la Dra. Ana Aguerre y la Dra. Alicia Tapia. A ellas mi gratitud. Al Dr. Carlos Landa y el Lic. Emanuel Montanari por sus aportes y lectura crítica de versiones previas.

\section{Referencias}

Appadurai, Arjun. 1986. «Introduction: Commodities and the Politics of Value», en The Social Life of Things, A. Appadurai, ed., pp. 3-63. Cambridge University Press. https://doi. org/10.1017/cbo9780511819582.003.

Aranda Jiménez, Gonzalo. 2008. «Introducción: somos lo que comemos. El significado social del consumo de alimentos y bebidas». Cuadernos de Prehistoria y Arqueología de la Universidad de Granada 18: 11-16.

Armaignac, Henry. 1974 (1883). Viaje por las pampas argentinas. Buenos Aires: Eudeba.

Arnould, Eric J. y Craig J. Thompson. 2005. «Consumer Culture Theory (CCT): Twenty Years of Research». Journal of Consumer Research 31: 868-883. https://doi. org/10.1086/426626.

Austral, Antonio y Ana María Rochietti. 1999. «Arqueología de frontera en el Pantanillo (Provincia de Córdoba). El Fuerte de Achiras», en Segundas Jornadas de investigadores en arqueología y etnohistoria. Primeras Jornadas de arqueología histórica y del contacto del centro-oeste del país y II Seminario de las ruinas de San Francisco, pp. 25-37. Universidad Nacional de Río Cuarto, Córdoba.

Avendaño, Santiago. 2000. Usos y costumbres de los indios de La Pampa, recopilación y edición de Meinrado Hux. Buenos Aires: Eudeba.

Babot, María del Pilar, María Marschoff y Francisco Pazzarelli, eds. 2012. Las manos en la masa: arqueologías, antropologías e historias de la alimentación en Suramérica. Córdoba: Universidad Nacional de Córdoba.

Babot, María del Pilar, Salomón Hocsman, Romina E. Piccón Figueroa y María Cecilia Haros. 2012. «Recetarios prehispánicos y tradiciones culinarias. Casos de la Puna Argentina», en Las manos en la masa: arqueologías, antropologías e historias de la alimentación en Suramérica, María del Pilar Babot et al., eds., pp. 235-270. Córdoba. Universidad Nacional de Córdoba.

Barros, Álvaro. 1975 (1982). Fronteras y territorios federales de las pampas del sur. Buenos Aires: Solar Hachette.

Baudrillard, Jean. 1983. Crítica de la economía política del signo. México: Siglo XXI.

Beaudry, Mary C., Lauren J. Cook y Stephen A. Mrozowski. 1996. «Artifacts and Active Voices: Material Culture as Social Discourse», en Images of the Recent Past, Charles E. Orser, ed., pp. 273-310. Walnut Creek: Altamira Press.

Berdichewsky, Bernardo. 2002. Antropología social: introducción. Una visión global de la humanidad. Santiago de Chile: LOM.

Binford, Lewis R. 1981. Bones: Ancient Men and Modern Myths. Nueva York: Academic Press. Blumenschine, Robert J. 1988. «An Experimental Model of the Timing of Hominid and Carnivore Influence on Archaeological Bone Assemblages». Journal of Archaeological Science 15 (5): 483-502. https://doi.org/10.1016/0305-4403(88)90078-7.

Bocock, Robert. 1996. Consumption. Londres: Routledge.

Bourdieu, Pierre. 1977. Outline of a Theory of Practice. Cambridge: Cambridge University Press. 
-1988. La distinción. Barcelona: Taurus.

- 1990. The Logic of Practice. Londres: Blackwell.

Braudel, Fernand. 1986. La dinámica del capitalismo. México: Fondo de Cultura Económica.

Burling, Robbins. 1976. «Teorías de maximización y el estudio de la antropología económica», en Antropología y economía, Maurice Godelier, comp., pp. 101-123. Barcelona: Anagrama.

Callejo, Javier. 1995. «Elementos para una teoría sociológica del consumo». Papers 47: 7596. https://doi.org/10.5565/rev/papers/v47n0.1800.

Carrasco Henríquez, Noelia. 2007. «Desarrollos de la antropología de la alimentación en América Latina: hacia el estudio de los problemas alimentarios contemporáneos». Estudios Sociales 16 (30): 80-101.

Carroll, Lynda. 1999. «Communities and Other Social Actors: Rethinking Commodities and Consumption in Global Historical Archaeology». International Journal of Historical Archaeology 3 (3): 131-136. https://doi.org/10.1023/a:1021953802048.

Certeau, Michel de. 1990. La invención de lo cotidiano. 1. Artes de hacer. México: Universidad Iberoamericana.

Contreras, Jesús. 1992. «Alimentación y cultura: Una reflexión desde la antropología». Revista Chilena de Antropología 11: 95-111. https://doi.org/10.5354/0719-1472.1992.17643.

Daza, José S. 1976 (1908). Episodios militares. Buenos Aires: Eudeba.

Delgado Salazar, Ramiro. 2000. «Comida y cultura: identidad y significado en el mundo contemporáneo». Estudios de Asia y África 36 (1): 83-108

Di Masso Tarditti, Marina. 2012. Redes alimentarias alternativas y soberanía alimentaria. Posibilidades para la transformación del sistema agroalimentario dominante. Tesis doctoral. Universitat Autònoma de Barcelona.

Díaz Méndez, Cecilia. 2005. «Los debates actuales en la Sociología de la alimentación». Revista Internacional de Sociología Tercera Época, 40: 47-78. https://doi.org/10.3989/ ris.2005.i40.189.

Döring, Adolf y Paul G. Lorentz. 1937 (1879). La conquista del desierto: diario de los miembros de la Comisión Científica de la expedición de 1879. Buenos Aires: Comisión Nacional Monumento al Teniente General Julio A. Roca.

Douglas, Mary. 1984. «Fundamental Issues in Food Problems». Current Anthropology 25 (4): 498-499. https://doi.org/10.1086/203168.

Douglas, Mary y Baron Isherwood. 1979. The World of Goods. Towards an Anthropology of Consumption. Nueva York: Basic Books. https://doi.org/10.4324/9780203434857.

Doval, Jimena. 2017. Abordaje zooarqueológico de las prácticas de consumo en asentamientos de frontera de la Pampa seca (fines del siglo XIX). Tesis doctoral. Universidad de Buenos Aires.

Doval, Jimena y Alicia H. Tapia. 2012. «¿Basural o acumulación natural de restos faunísticos? Análisis zooarqueológico del Fortín La Perra (1883-1885), La Pampa». Comechingonia 16 (2): 9-30.

- 2013. «Consumo de fauna domesticada y silvestre en el Fortín La Perra (1883-1885), La Pampa». Relaciones de la Sociedad Argentina de Antropología 38 (2): 459-492.

Ébelot, Alfred. 1968 (1880). Frontera sur. Recuerdos y relatos de la campaña del desierto. Buenos Aires: Kraft.

Flandrin, Jean-Louis y Massimo Montanari, eds. 2004 (1996). Historia de la alimentación. Gijón: Ediciones Trea.

Fotheringham, Ignacio H. 1970 (1908). La vida de un soldado o reminiscencias de la frontera. Buenos Aires: Kraft. 
García Canclini, Néstor. 1984. Ideología y cultura. Cursos y conferencias. Buenos Aires: Universidad de Buenos Aires.

Garine, Igor de. 1999. «Antropología de la alimentación: entre naturaleza y cultura», en Alimentación y cultura: actas del congreso internacional, pp. 13-34. Huesca: La Val de Onsera.

Giddens, Anthony. 1984. The Constitution of Society. Cambridge: Polity Press.

Glennie, Paul. 1995. «Consumption within Historical Studies», en Acknowledging Consumption, Daniel Miller, ed., pp.164-203. Londres: Routledge.

Goffman, Erving. 1997. La presentación de la persona en la vida cotidiana. Buenos Aires: Amorrortu.

Gómez Romero, Facundo y Mariano Ramos. 1994. «Miñana Fortlet: Historical Archaeology Research». Arqueología Histórica en América Latina 2: 15-30.

Gómez Romero, Facundo y Julio César Spota. 2006. «Algunos comentarios críticos acerca de 15 años de arqueología en los fortines pampeanos». Relaciones de la Sociedad Argentina de Antropología 31: 161-185

Gomila, Teófilo Carlos. 2011. Memorias de frontera y otros escritos, recopilación y edición de Ingrid De Jong y Valeria Satas. Buenos Aires: El Elefante Blanco.

Goody, Jack. 1995. Cocina, cuisine y clase. Estudio de sociología comparada. Barcelona: Gedisa.

Gosden, Chris e Yvonne Marshall. 1999. «The Cultural Biography of Objects». World Archaeology 31 (2): 169-178. https://doi.org/10.1080/00438243.1999.9980439.

Guerrino, Antonio Alberto. 1979. La medicina en la Campaña del Desierto. Buenos Aires: Círculo Militar.

Guinard, Auguste. 1961 (1856). Tres años de cautividad entre los patagones. Buenos Aires: Eudeba.

Gutiérrez, Eduardo. 1964 (1909). Croquis y siluetas militares. Buenos Aires: Eudeba.

Herskovits, Melville. 1952. Antropología económica. Estudio de economía comparada. México: Fondo de Cultura Económica.

Hobsbawm, Eric. 1998a. La era del capital, 1848-1875. Barcelona: Crítica.

. 1998b. La era del imperio, 1875-1914. Barcelona: Crítica.

Hodder, Ian. 1988. Interpretación en arqueología. Barcelona: Crítica.

Isaac, Glynn. 1983. «Bones in Contention: Competing Explanations for the Juxtaposition of Early Pleistocene Artefacts and Faunal Remains», en Animals and Archaeology. Hunters and their Prey, J. Clutton-Brock y C. Grigson, eds., pp 3-19. BAR International Series, 163. Oxford.

Kaplan, David. 1976. «La controversia formalistas-substantivistas de la antropología económica: reflexiones sobre sus amplias implicaciones», en Antropología y economía, Maurice Godelier, ed., pp. 208-232. Barcelona: Anagrama.

Kent, Susan. 1993. «Variability in Faunal Assemblages: The Influence of Hunting Skill, Sharing, Dogs and Mode of Cooking on Faunal Remains at a Sedentary Kalahari Community». Journal of Anthropological Archaeology 12: 325-385.

Landa, Carlos. 2010. Los materiales de metal como indicadores de identidad y diferenciación social en la Frontera del Sur (1776-1885). Tesis doctoral. Universidad de Buenos Aires. http://repositorio.filo.uba.ar/handle/filodigital/1320.

Leakey, Mary D. 1971. Olduvai Gorge, vol. 3. Excavations in Bed I and II, 1960-63. Cambridge: Cambridge University Press.

Lee, Richard B. e Irven DeVore, eds. 1968. Man the Hunter. Chicago: Aldine.

Mansilla, Lucio V. 2006 (1870). Excursión a los indios ranqueles. Buenos Aires: Gradifco. 
Marschof, María. 2007. Gato por liebre. Prácticas alimenticias en Floridablanca. Buenos Aires: Teseo.

_. 2008. «Los objetos de la alimentación: una mirada arqueológica a los inventarios post mortem del Buenos Aires virreinal», en Mamül Mapu: pasado y presente desde la arqueología pampeana, M. Berón et al., eds., pp. 215-228. Ayacucho: Editorial Libros del Espinillo.

Memoria... 1885. Memoria del Ministerio de Guerra y Marina. Años 1860-1885. Archivo General de la Nación y Biblioteca del Ministerio de Defensa de la Nación, Buenos Aires.

Michael, Robert T. y Gary S. Becker. 1973. «On the New Theory of Consumer Behavior». The Swedish Journal of Economics 75 (4): 378-396. https://doi.org/10.2307/3439147.

Miele, Mara. 2006. «Consumption Culture: The Case of Food», en Handbook of Rural Studies, Paul Cloke, Terry Marsden y Patrick Mooney, eds., pp. 344-354. Londres: Sage. https://doi.org/10.4135/9781848608016.n24.

Miller, Daniel. 1987. Material Culture and Mass Consumption. Oxford: Blackwell.

1991. «Absolute Freedom in Trinidad». Man New Series 26 (2): 323-341. https://doi. org/10.2307/2803835.

- 1995. «Consumption and Commodities». Annual Review Anthropology 24: 141161. https://doi.org/10.1146/annurev.anthro.24.1.141.

Mintz, Sidney W. y Christine M. Du Bois. 2002. «The Anthropology of Food and Eating». Annual Review Anthropology 31: 99-119. https://doi.org/10.1146/annurev. anthro.32.032702.131011.

Molina, José Luis. 2004. Manual de antropología económica. Barcelona: Universitat Autònoma de Barcelona.

Montanari, Emanuel. 2013. Los ranqueles y la última frontera. Análisis arqueofaunístico del sitio Don Isidoro 2, provincia de La Pampa (1878-79). Tesis de licenciatura. Universidad de Buenos Aires.

Nastri, Javier. 2004. «La arqueología argentina y la primacía del objeto», en Teoría arquelógica en América del Sur, Gustavo G. Politis y Roberto D. Peretti, eds., pp. 213-231. Olavarría: Incuapa.

Olascoaga, Manuel J. 1974 (1880). Estudio topográfico de La Pampa y Río Negro. Buenos Aires: Ediciones Ostwald Martínez.

Orbigny, Alcide d'. 1999 (1846). Viaje por la América meridional II. Buenos Aires: Emecé.

Parchappe, Narciso. 1977 (1828). Expedición fundadora del Fuerte 25 de Mayo en Cruz de Guerra, año 1828. Buenos Aires: Eudeba.

Paynter, Robert. 2000. «Historical Archaeology and the post-Columbian World of North America». Journal of Archaeological Research 8 (3): 169-217

Pérez Samper, María de los Ángeles. 2010. «La alimentación española del siglo XVIII vista por los viajeros británicos». Tiempos Modernos: Revista Electrónica de Historia Moderna 7 (21). http://www.tiemposmodernos.org/tm3/index.php/tm/article/view/228.

Pineau, Virginia. 2011. Las bebidas alcohólicas en las relaciones entre aborígenes y militares. Análisis arqueológico en la Frontera del Sur Argentina - Siglos XVIII-XIX. Editorial Académica Española.

Pineau, Virginia y Carlos Landa. 2009. «Confieso que he bebido... Comparación de dos fortines de la frontera sur en relación con la provisión y el consumo de bebidas alcohólicas (1860-1885)». Arqueología Suramericana 5: 138-152.

Polanyi, Karl. 2007 (1944). La gran transformación. Los orígenes políticos y económicos de nuestro tiempo. Buenos Aires: Fondo de Cultura Económica.

Potts, Richard. 1984. «Home Base and Early Hominids». American Scientist 92: 338-349 
Prado, Manuel. 1960 (1907). La guerra al malón. Buenos Aires: Eudeba.

—. 2005 (1892). Conquista de La Pampa. Cuadros de la guerra de fronteras. Buenos Aires: Taurus.

Quintana, Carlos A. 2008. «Cálculo del número mínimo de individuos de huevos de ñandú». Intersecciones en Antropología 9: 93-97.

Racedo, Eduardo. 1940 (1879). La conquista del desierto. Buenos Aires: Plus Ultra.

Rose, Lisa y Fiona Marshall. 1996. «Meat Eating, Hominid Society and Home Bases Revisited». Current Anthropology 37 (2): 307-338. https://doi.org/10.1086/204494.

Rotman, Mónica B. 1996. «Apuntes para una discusión de las teorías del consumo», en $A n$ tropología económica. Ficciones y producciones del hombre económico, Hugo Trinchero, ed., pp. 167-186. Buenos Aires: Eudeba.

Samuel, Delwen. 1996. «Approaches to the Archaeology of Food», en Petit Propos Culinaires 54. Essays and Notes on Food, Cookery and Cookery Books, pp. 12-21. Londres: Prospect Books.

Schiffer, Michael B. 1972. «Archaeological Context and Systemic Context». American Antiquity 37 (2): 156-165. https://doi.org/10.2307/278203.

Schoeninger, Margaret J. y Mark R. Schurr. 1994. «Interpreting Carbon Stable Isotope Ratios», en Corn and Culture in the Prehistoric New World, Sissel Johannessen y Christine Ann Hastorf, eds., pp. 55-66. Boulder: Westview Press.

Seymour, Richard A. 2013 (1869). Un poblador de las pampas. Buenos Aires: El Elefante Blanco. Shanks, Michael y Christopher Tilley. 1987. Social Theory and Archaeology. University of New Mexico Press, Albuquerque.

Shipman, Pat. 1984. «Scavenger Hunt». Natural History 93 (4): 20-27.

Shove, Elizabeth, Frank Trentmann y Richard Wilk, eds. 2009. Time, Consumption and Everyday Life: Practice, Materiality and Culture. Oxford: Berg.

Spencer-Wood, Suzanne M. 1987. «A Survey of Domestic Reform Movement Sites in Boston and Cambridge, ca.1865-1905». Historical Archaeology 21 (2): 7-36. https://doi. org/10.1007/bf03373484.

Spota, Julio César. 2010. «Acero, desierto y sangre. Expectativas arqueológicas del conflicto armado entre militares y aborígenes en la Pampa seca (1877-1879)», en De ranqueles, militares y religiosos en el Mamül Mapu: enfoque arqueológico y etnohistórico, Alicia H. Tapia, ed., pp. 5-109. Buenos Aires: Universidad de Buenos Aires.

Tamayo Téllez, Migdalia. 2011. «La perspectiva sociológica latinoamericana en los estudios del consumo». Santiago 126 (3): 171-180. Santiago de Cuba.

Tapia, Alicia H. 2008. Arqueología histórica de los cacicazgos ranqueles (siglos XVIII a $X I X)$. Tesis doctoral. Universidad de Buenos Aires.

Trinchero, Héctor Hugo. 1998. Antropología económica: ficciones y producciones del hombre económico. Buenos Aires: EUDEBA.

Vries, Jan de. 2008. The Industrious Revolution. Consumer Behavior and the Household Economy, 1650 to the Present. Cambridge: Cambridge University Press. https://doi. org/10.1017/cbo9780511818196.

Wurst, LouAnn y Randall H. McGuire. 1999. «Immaculate Consumption: A Critique of the 'Shop till you Drop' School of Human Behavior». International Journal of Historical Archaeology 3 (3): 191-199. https://doi.org/10.1023/a:1021914220703.

Zeballos, Estanislao S. 2002 (1881). Viaje al país de los araucanos. Buenos Aires: El Elefante Blanco. 
Zurro, Débora. 2006. «El análisis de fitolitos y su papel en el estudio del consumo de recursos vegetales en la prehistoria: bases para una propuesta metodológica materialista». Trabajos de Prehistoria 63 (2): 35-54. https://doi.org/10.3989/tp.2006.v63.i2.16. 